\title{
Welcome to cardboard country: how plain packaging could change the subjective experience of smoking
}

\author{
Melanie Wakefield
}

\begin{abstract}
The Australian government's announcement that it will require all cigarettes sold from July 2012 to be contained in olive brown packages devoid of brand design elements except for their brand name in a standardised font and location $^{1-3}$ recognises Australia's serious commitment as a signatory to the WHO Framework Convention on Tobacco Control. ${ }^{4}$ The announcement of this world-first legislation was the subject of intense media coverage $^{5}$ (see page 361) and the path towards its realisation has continued to come under incendiary attack from tobacco companies and allied front groups, ${ }^{6}$ who are desperate to prevent its implementation in Australia and replication in other nations.
\end{abstract}

While there is good evidence from experimental studies that plain packaging will reduce brand appeal, correct erroneous beliefs about the harms of smoking and increase the salience of health warnings on packs, ${ }^{6}$ Moodie and colleagues ${ }^{7}$ (see page 367 ) of this issue have added a new dimension to the literature and identified another possible benefit. Smokers were provided with plain brown packs labelled with a neutral brand name into which to decant their usual cigarettes for 2 weeks, and their experiences were compared with a 2 -week period of smoking their cigarettes from branded packs. Although a small study with high attrition and incomplete compliance, the findings were notable. The experience of smoking cigarettes from plain brown packs was reportedly less enjoyable and less satisfying for smokers than those same cigarettes when smoked from their regularly branded packs. Further, some evidence of avoidance of smoking was observed when cigarettes were enclosed in plain

Correspondence to Melanie Wakefield, Director, Centre for Behavioural Research in Cancer, Cancer Council Victoria, Melbourne, Australia;

melanie.wakefield@cancervic.org.au rather than branded packs, by smokers concealing the pack, smoking fewer cigarettes and thinking more about quitting. While no naturalistic study can replicate the real-world implementation of the proposed plain packaging legislation where the packs of every Australian smoker would ultimately be the same unappealing brown, it is worth reflecting that the pattern of observed findings is entirely consistent with a much wider body of evidence that branding and labelling can modify the actual subjective experience of products when they are consumed.

As early as the 1970s, a published study reported on smokers who had been randomly assigned to smoke identical cigarettes branded as either 'April' or 'Frontiersman'. Female smokers who smoked the femininely branded cigarettes rated all aspects of taste and enjoyment more favourably than the female smokers who tried the identical cigarettes with the masculine name, while male smokers favoured the masculine brand, although the effect was less pronounced. By far the best evidence that branding influences subjectively experienced tobacco taste in fact comes from the tobacco industry's own internal documents, which detail numerous market testing studies where identical cigarettes, when presented in packs with varied designs, colours and other branding elements, led consumers to experience and evaluate them differently when they were smoked. ${ }^{9}{ }^{10}$ For example, identical cigarettes were described after being smoked as 'too mild,' 'not easy drawing' and 'burn too fast,' when presented in blue packs, but as 'too strong' and 'harsher' when presented in red packs. ${ }^{9}$ DiFranza et al ${ }^{10}$ noted that the influence of pack design on the subjectively experienced qualities of the cigarette was of such a magnitude that when purely objective ratings of the cigarette's qualities were desired, tobacco companies used unbranded test cigarettes.
The wider consumer marketing literature shows convincingly that the taste of food and drinks is able to be manipulated by branding and labelling. ${ }^{11}{ }^{12}$ This research recognises that the use of branding, including the use of colour and descriptive names, results in an expectation or sensory halo effect, whereby the expectation influences how a person thinks a product might taste, which then influences one's taste perceptions and liking when the product is actually consumed. ${ }^{12}$

For example, bitter coffee was appraised after sampling as tasting less bitter only among those consumers who were exposed beforehand to three advertisements asserting that the coffee was not bitter. ${ }^{13}$ People who tasted an energy bar labelled as containing soy protein were more likely to rate it as 'grainy' and 'tasteless' compared with identical bars that contained no mention of soy (although neither bar actually contained soy). ${ }^{14}$ Descriptive names of cafeteria meals ('Succulent Italian Seafood Filet') led to meals being rated after consumption as more appealing, tastier and caloric than identical meals with less descriptive names ('Seafood Filet'). ${ }^{15}$ Brown-coloured M\&M candies were rated as more 'chocolatey' than all other colours, and those labelled as 'dark chocolate' were rated as more 'chocolatey' than those labelled 'milk chocolate' although they were otherwise identical. ${ }^{16}$ These effects are not just confined to adults: identical food products were appraised as tasting better by young children when branded with 'McDonald's' than when unbranded; ${ }^{17}$ young children reported higher subjective taste ratings of cereals ${ }^{18}$ and preferred the taste of snack foods ${ }^{19}$ when their packs featured popular licensed cartoon characters than when they did not.

Intriguingly, expectancies can change the subjective evaluation of a product and the brain's response to it as it is being consumed. Just as Coke was rated higher in a subjective taste test when consumed from a cup with the Coke logo than without, the image of a Coke can presented prior to Coke tasting resulted in greater brain activity in key brain regions implicated in processing emotion, compared with unbranded Coke delivery. ${ }^{20}$ In another study, when people tasted a highly bitter fluid, the level of activation in the bilateral taste cortex in the brain was reduced when they were told it would be only mildly unpleasant than when told it would be highly unpleasant. ${ }^{21}$ Studies such as these imply that branding and 
labelling can lead people to hold more favourable expectations about a product, and these expectations influence brain functions in ways that result in an enhanced sensory experience.

Most consumers do not think that knowledge of branding before tasting a product would change their sensed experience of it and remain unable to correctly predict the results of taste tests in which expectancies are manipulated in the ways described (eg, Lee et $a l^{22}$ ). The influence of branding on sensed experience when products are consumed occurs largely outside conscious awareness, most likely because consumers generally rely on short cuts or heuristics-easily available information that is rapidly processed-to guide their evaluation. ${ }^{12}$ In other words, consumers are effectively being manipulated in an under-the-radar fashion by carefully tested branding and design, subtly raising their expectations that the product will offer a positive experience and thereby increasing the likelihood that their ultimate experience of it will follow suit.

In the case of a deadly product such as tobacco, there is no place for powerful branding imagery on packs if it serves to promote greater subjective enjoyment of smoking, leading consumers to extend their smoking careers. Tobacco companies likely fear privately that plain packaging will reverse-engineer their clever branding tricks: the halo effects of boring standard brown packs could lead smokers closer to subjectively tasting their cigarettes as more like the toxic smoke delivery devices they really are.

Competing interests None.

Provenance and peer review Commissioned; not externally peer reviewed.

Tobacco Control 2011;20:321-322.

doi:10.1136/tc.2011.044446

\section{REFERENCES}

1. Rudd K, Swan W, Roxon N. Prime Minister, Treasurer, Minister for Health. Anti-Smoking Action. [Media release]. Canberra: Office of the Prime Minister, 2010. http://www.alp.org.au/federalgovernment/news/anti-smoking-action/ laccessed 10 Jul 2011).

2. Australian Government. Public Consultation on Plain Packaging of Tobacco Products. Canberra: Department of Health and Ageing, 2011. http:// yourhealth.gov.au/internet/yourhealth/publishing.nsf/ Content/plainpack-tobacco.

3. Tobacco Plain Packaging Bill 2011-Exposure Draft 2011. http://yourhealth.gov.au/internet/yourhealth/ publishing.nsf/Content/tpp-bill2011.

4. World Health Organisation. Framework Convention on Tobacco Control. New York: United Nations, 2003: 2302. http://www.who.int/tobacco/ framework/WHO FCTC english.pdf.

5. Freeman B. Tobacco plain packaging legislation: a content analysis of commentary posted on Australian online news. Tob Control 2011;20:361-6.

6. Quit Victoria, Cancer Council Victoria. Plain packaging of tobacco products: a review of the evidence. Cancer Council Australia, 2011. http://bit. ly/jmWu36.

7. Moodie C, Mackintosh AM, Hastings G, et al. Young adult smokers' perceptions of plain packaging: a pilot naturalistic study. Tob Control 2011;20:367-73.

8. Friedman HH, Dipple WS. The effect of masculine and feminine brand names on the perceived taste of a cigarette. Decision Sci 1978;9:467-71.

9. Wakefield M, Morley C, Horan JK, et al. The cigarette pack as image: new evidence from tobacco industry documents. Tob Control 2002;11 (Suppl I):i73-80.

10. Difranza JR, Clark DW, Pollay RW. Cigarette package design: opportunities for disease prevention Tob Induced Dis 2002;1:97-109.

11. Deliza R, McFie HJH. The generation of sensory expectation by external cues and its effects on sensory perception and hedonic ratings: a review. $J$ Sens Stud 1996;11:103-28.

12. Cardello AV. Measuring consumer expectation to improve food product development. In: MacFie $\mathrm{H}$, ed. Consumer-led Food Product Development. Cambridge: Woodhead Publishing in Food Science, Technology and Nutrition, 2007:223-61.

13. Olson JC, Dover PA. Cognitive effects of deceptive advertising. J Marketing Res 1978;15:29-38.

14. Wansink B, Park SB. Sensory suggestiveness and labeling: do soy labels bias taste? J Sens Stud 2002 17(5):483-91.

15. Wansink B, Van Ittersum K, Painter JE. How descriptive names bias sensory perception in restaurants. Food Qual Preference 2005;16:393-400.

16. Shankar M, Levitan CA, Prescott J, et al. The influence of color and label information on flavor perception. Chemosens Perc 2009;2:53-8.

17. Robinson TN, Borzekowski DL, Matheson DM, et al. Effects of fast food branding on young children's taste preferences. Arch Pediatr Adolesc Med 2007:161:792-7.

18. Lapierre MA, Vaala SE, Linebarger DL. Influence of licensed spokescharacters and health cues on children's ratings of cereal taste. Arch Pediatr Adolesc Med 2011;:165:229-34.

19. Roberto CA, Baik J, Harris JL, et al. Influence of licensed characters on children's taste and snack preferences. Pediatrics 2010;126:88-93.

20. McClure SM, Li J, Tomlin D, et al. Neural correlates of behavioral preference for culturally familiar drinks. Neuron 2004;44:379-87.

21. Nitschke JB, Dixon GE, Sarinopoulos I, et al. Altering expectancy dampens neural response to aversive taste in primary taste cortex. Nat Neurosci 2006:9:435-42.

22. Lee L, Frederick S, Ariely D. Try it, you'll like it: the influence of expectation, consumption, and revelation on preferences for beer. Psychol Sci 2006;17:1054-8. 